\title{
Induction of Labor for Maternal Indications at a Periviable Gestational Age; Survey on Management, Reporting and Auditing amongst Dutch Maternal-Fetal Medicine Specialists and Neonatologists
}

\author{
Leonoor van Eerden, $\mathrm{MD}^{1}$ Christianne J.M. de Groot, MD, PhD ${ }^{1}$
}

Godelieve C.M.L. Page-Christiaens, MD, PhD ${ }^{2}$ Eva Pajkrt, MD, PhD ${ }^{3}$ Gerda G. Zeeman, MD, PhD 4

Antoinette C. Bolte, MD, PhD 5

1 Department of Obstetrics and Gynecology, VU Medical Center
Amsterdam, Amsterdam, the Netherlands
2 Department of Obstetrics and Gynecology, University Medical
Center Utrecht, Utrecht, the Netherlands
${ }^{3}$ Department of Obstetrics and Gynecology, Eva Pajkrt, Academic
Medical Center Amsterdam, Amsterdam, the Netherlands
${ }^{4}$ Department of Obstetrics and Gynecology, University Medical
Center Groningen, Groningen, the Netherlands
${ }^{5}$ Department of Obstetrics and Gynecology, Radboud University
Medical Center Nijmegen, Nijmegen, Gelderland, the Netherlands

Address for correspondence Leonoor van Eerden, MD, Department of Obstetrics and Gynecology, Maasstad Hospital, Maasstadweg 21, 3079 DZ Rotterdam, the Netherlands (e-mail: eerdenl@maasstadziekenhuis.nl).

Am J Perinatol Rep 2018;8:e295-e300.

\begin{abstract}
Keywords

- termination of pregnancy

- legislation

- survey

- MFM specialists

- neonatologists

Background In cases of life-threatening maternal conditions in the periviable period, professionals may consider immediate delivery with fetal demise as a consequence of the treatment. We sought the opinion of involved medical professionals on management, reporting, and auditing in these cases.

Methods We performed an online survey amongst all registered maternal-fetal medicine (MFM) specialists and neonatologists in the Netherlands. The survey presented two hypothetical cases of severe early-onset pre-eclampsia at periviable gestational ages. Management consisted of immediate termination or expectant management directed towards newborn survival.

Findings In the case managed by immediate termination, $62 \%$ percent answered that fetal demise resulting from induction of labor for maternal indications should be audited only within the medical profession. In the case of expectant management, $17 \%$ of the participants agreed with this management. Some answers revealed a significant difference in opinion between the medical specialists.

Conclusion Perspective of MFM specialists and neonatologists differs with regard to counseling prospect parents in case of severe early onset pre-eclampsia. The majority of professionals is willing to report late termination (after 24 weeks' gestation) for severe maternal disease to medical experts for internal audits but not for legal auditing.
\end{abstract}

received

March 15, 2018

accepted

September 5, 2018
DOI https://doi.org/

10.1055/s-0038-1675340. ISSN 2157-6998.
Copyright $\odot 2018$ by Thieme Medical Publishers, Inc., 333 Seventh Avenue, New York, NY 10001, USA. Tel: +1(212) 584-4662.
License terms

(c) (1) $\ominus$ (\$) 
Dutch legislation on termination of pregnancy has been in place since the 1981 and regulations on termination of pregnancy after 24 weeks' gestation, the so called 'late terminations', since 2007. In 2016 Dutch regulations for late termination of pregnancy have been revised by the Ministries of Justice and Health to promote reporting and auditing. This was preceded by a formal evaluation of the existing regulations and a debate amongst professionals. The current study was done in the framework of this debate.

In the Netherlands termination of pregnancy is subject to a number conditions, such as parental request and reflection time, exempted from legal prosecution up to the moment where the newborn is judged to be viable outside the womb. This is usually considered to be after $24^{0 / 7}$ weeks of gestation for adequately grown fetuses with a sufficient amount of amniotic fluid for lung development and without life-threatening congenital disorders. ${ }^{1}$

Termination for nonmedical reasons is usually performed in licensed abortion clinics up to 22 weeks. Terminations for genetic reasons or medical maternal disorders are performed in obstetric units of secondary or tertiary care hospitals. In the Netherlands, approximately 30,000 pregnancies are terminated up to 24 weeks on an annual base. Half of these take place before 7 weeks' gestation and 3\% after 21 weeks. Twelve percent of women undergoing termination of pregnancy are not residing in the Netherlands. There is an annual report of the Health Care Inspectorate in an aggregated form. ${ }^{2}$

In case of termination beyond 24 weeks, the procedure is the following: every death of a minor, including induced or spontaneous stillbirth after $24^{0 / 7}$ weeks has to be reported to the Municipal Coroner who then reports to the District Attorney. ${ }^{3}$ This also accounts for neonatal deaths on neonatal care units as well as fetal demise during labor and delivery. Up to the early 2016 the cases of termination were further subject to review by one of two expert committees. ${ }^{4}$ In case of lethalfetal disorders, the so-called category 1 , a committee of the Dutch Society of Obstetrics and Gynecology performed an internal audit and reported anonymous and aggregated to the member gynecologists as well as to the Dutch Health Care Inspectorate. Category 2 pertained to cases with severe but not necessarily lethal disorders where neonatologists would refrain from senseless postnatal intervention. Cases in this category were audited by a committee appointed by the Ministries of Justice and Health ${ }^{4}$ and reported on a case by case basis to the Attorney General, the highest legal authority in the Netherlands. As from the early 2016 both committees have been merged. The current committee consists of four medical specialists, one lawyer and one ethicist. ${ }^{5}$

Induction of labor for maternal indications at a periviable gestational age was noted in the former regulation but not extensively addressed. In the new regulation, cases of induction of labor for maternal indications do not have to be reported to the aforementioned committee. Annually, there are approximately 25 terminations of pregnancy for maternal indications in the Netherlands. ${ }^{6}$ Approximately 12 of these take place at or shortly after 24 weeks. Up to now these cases were rarely reported to the District Attorney, because fetal demise was considered the inevitable consequence of the treatment of the mother, and because of lack of clear guidelines. With our survey we aimed to help clarify the issues at stake. Also the results of this survey can be used to reopen the discussion amongst professionals and gain uniformity of registration and auditing in a newly developed registration system after introduction of the new regulations.

\section{Design and Methods}

\section{Survey Design}

All registered maternal-fetal medicine (MFM) specialists and neonatologists in the Netherlands were invited to participate in an online survey, using a commercial internet-based service (surveymonkey.com). Both disciplines are involved as well in patient counseling as in the evaluation of the regulations. We approached both disciplines separately. The survey invitation included a cover letter stating the study's objective, the voluntary and anonymous nature of the study, the intent to use the data in a publication, and contact information. By completing the survey, the participants consented to these terms. The ethical advisory board of the VU Medical Centre evaluated the survey and exempted the study from formal ethical review (VUmc 29-2010/200). ${ }^{7}$

The survey presented two hypothetical cases of severe preeclampsia in combination with dismal fetal prospects based on historical patient records. The cases are summarized in -Figs. 1 and $\mathbf{2}$.

The survey questions were pretested by eight reviewers who were representative for the study population. The reviewers assessed clarity and content, order of questions, and total time needed to complete the survey. The final survey consisted of seven multiple answer questions. The four questions accompanying the first case were on reporting and auditing and the three questions accompanying the second case were on management. It took approximately 10 minutes to complete the survey.

\section{Survey Distribution}

An invitation with a link to the survey was sent by an e-mail to all MFM specialists $(n=197)$ and neonatologists $(n=282)$ registered in the Netherlands either as a member of the Dutch Society of Obstetrics and Gynecology or the Pediatric Association of the Netherlands in 2015. Two months after the initial approach we sent a reminder. Four months after the first invitation, the survey was closed.

\section{Data Management}

Results are presented as absolute numbers and percentages. Statistical analysis was performed with SPSS 20.0 (SPSS Inc., Chicago, IL). Differences were tested with a Fisher's exact test as appropriate. $p$-Values less than 0.05 were considered statistically significant.

\section{Results}

The overall response rate was $37 \%$ (175), $34 \%$ amongst the MFM specialists $(n=66)$ and $39 \%$ amongst the neonatologists $(n=109)$. 


\begin{abstract}
Case 1:
A 20 year old primigravid woman is admitted to the hospital with preeclampsia at a gestational

age of $24^{2 / 7}$ weeks. She is treated with antihypertensive medication and magnesiumsulphate

to prevent eclampsia. Fetal ultrasound shows signs of severe growth restriction (EFW 359

grams) and an abnormal flow profile in the umbilical artery. At a gestational age of 25 weeks

her condition deteriorates and the decision is made to terminate the pregnancy in order to

prevent worse maternal outcome. Because of the severe fetal growth restriction labor is

induced with prostaglandins. No fetal monitoring is performed. She delivers a still born son

with a birth weight of 412 grams. She makes a full recovery within one week.

Questions:

- Do you think this case should have been reported to the municipal coroner?

- Do you think such cases should be audited by either the professional society or by the district Attorney or by both or by neither?

- Are you willing to report such cases to the committee of The Dutch Society of Obstetrics and Gynecologists for an internal audit?

- Do you think such cases should be reported to an expert committee appointed by the ministries of Health and Justice?
\end{abstract}

Fig. 1 Case 1: Possible answers consist of yes, no, I don't know, and a free text option.

Answers to questions on case 1 are shown in - Tables 1 and 2. In this case, labor was induced for severe early-onset pre-eclampsia after a gestational age of 24 weeks with an estimated fetal weight (EFW) of 359 grams. Fetal demise was not reported to the Municipal Coroner (-Fig. 1).

Sixty-two percent of the participants believed that fetal demise as a result of induction of labor for maternal indications should be subject to auditing within the medical profession only and that it should never be subject to legal audit (-Table 1).

Fifty percent of the respondents argued that this case should have been reported to the Municipal Coroner. Furthermore, $73 \%$ of all participants would be willing to report cases of termination for maternal indications resulting in fetal demise to an expert committee of the Dutch Society of Obstetrics and Gynecology. Thirty-three percent of all participants would be willing to report these cases to an expert committee appointed by the Ministries of Health and Justice, advising the Attorney General whether or not to prosecute the MFM specialist (-Table 2 ).

Fourteen percent $(n=22)$ of participants recorded specific reasons in the free text box for their hesitation to report induction of labor for severe early-onset pre-eclampsia at a periviable gestational age to the expert committee appointed by the Ministries of Justice and Health. The given answers were: there are no other treatment options for the mother besides immediate delivery $(n=9)$ and fear of legal judgment could delay appropriate care $(n=4)$. Six respondents felt that a multidisciplinary consultation and consensus between the involved medical specialties prior to the decision to induce labor should be sufficient. Three participants feared legal prosecution.

Answers to questions on case 2 are shown in - Table 3 . In this case, the patient developed severe early onset preeclampsia at a gestational age of $23^{2 / 7}$ weeks. During expectant management, she suffered multiple eclamptic seizures. At a gestational age of 25 weeks, a caesarean section was performed. The mother has residual symptoms; the baby girl did not survive (-Fig. 2).

Only $17 \%$ of the participants agreed with the chosen expectant management and most of these were neonatologists (-Table 3). Seventy-five percent of MFM specialist answered that an eclamptic seizure is always a reason to terminate the pregnancy. Thirty-three percent of participants stated that they would have delivered via caesarean section even prior to 25 weeks. Neonatologists were more in favor of a caesarean section than MFM specialists.

At the end of the survey there was a free text box for recommendations and remarks. Twenty-one neonatologists (19\%) mentioned that the parents' wishes should be leading in the choice between induction of labor versus active management. Eighteen (27\%) MFM specialists gave a remark of which 13 (20\%) stated that the maternal condition should 


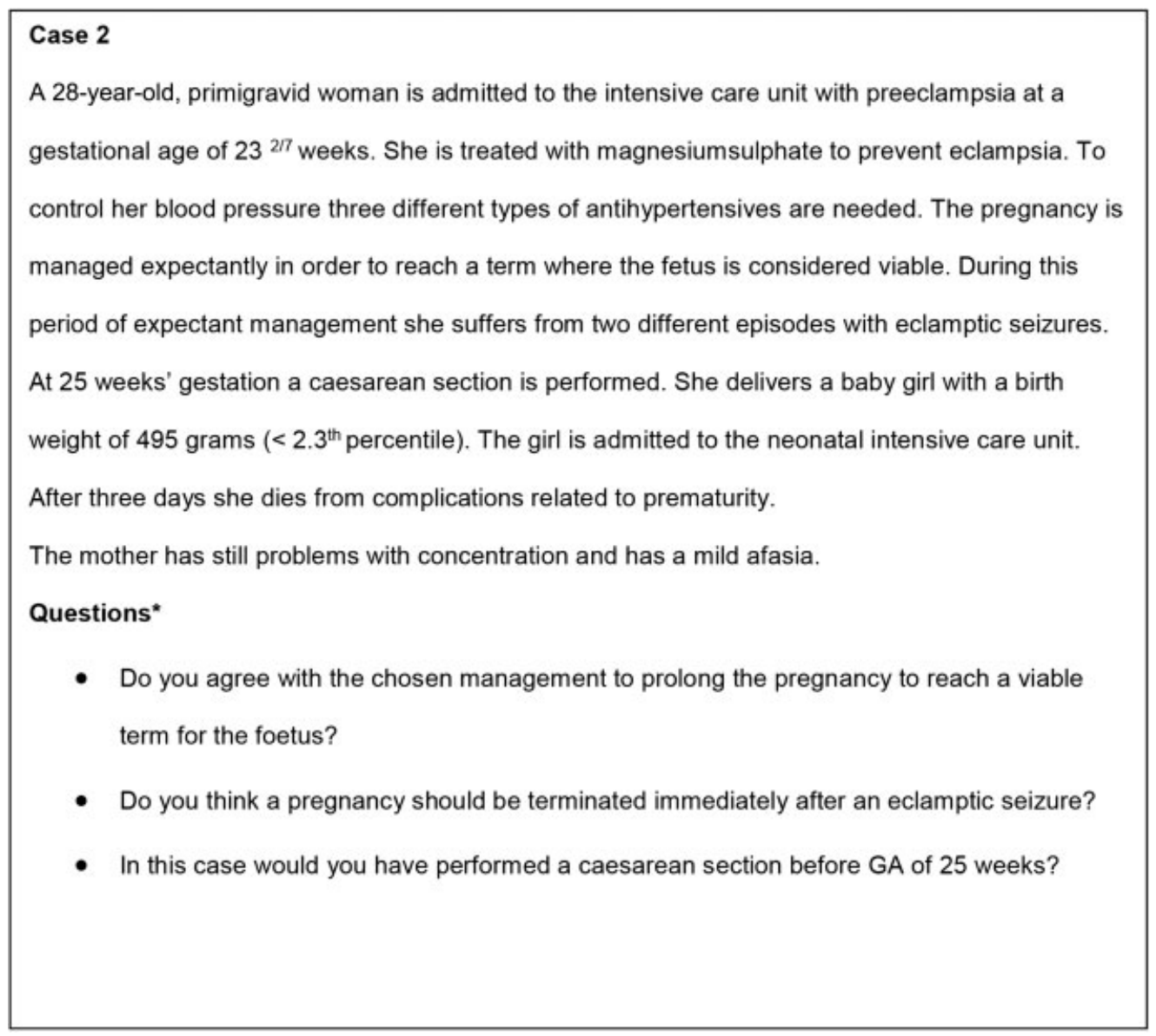

Fig. 2 Case 2: Possible answers consist of yes, no, I don't know, and a free text option.

Table 1 (Case 1): Question: do you think these cases should be subject to audits? If yes, what kind of audit?

\begin{tabular}{|l|l|l|l|l|}
\hline Profession & $\begin{array}{l}\text { Peers } \\
\text { only } \\
(\%)\end{array}$ & $\begin{array}{l}\text { Legal } \\
\text { only } \\
(\%)\end{array}$ & $\begin{array}{l}\text { Both } \\
(\%)\end{array}$ & $\begin{array}{l}\text { None } \\
(\%)\end{array}$ \\
\hline $\begin{array}{l}\text { MFM } \\
\text { specialists }\end{array}$ & $42(67)^{\mathrm{a}}$ & - & $11(17)^{\mathrm{a}}$ & $10(16)^{\mathrm{a}}$ \\
\hline Neonatologists & $59(60)^{\mathrm{a}}$ & $3(3)^{\mathrm{a}}$ & $14(14)^{\mathrm{a}}$ & $23(23)^{\mathrm{a}}$ \\
\hline Total & $101(62)$ & $3(2)$ & $25(15)$ & $34(21)$ \\
\hline
\end{tabular}

Note: Numbers are presented as absolute numbers according to profession.

${ }^{a}$ percentages are shown as percentages within the profession.

be leading in the choice between immediate delivery versus expectant management. Only five MFM specialists shared the opinion with the neonatologists that the parents' wishes should be leading ( $8 \%$ ).

\section{Discussion}

As part of an active debate on the procedures to be followed in case of late termination of pregnancy for maternal indications, this study interrogated the opinion of MFM specialists
Table 2 Answers to the questions on case 1

\begin{tabular}{|c|c|c|c|c|}
\hline Profession & Yes (\%) & No (\%) & $\begin{array}{l}\text { Unknown } \\
(\%)\end{array}$ & $p$-Value \\
\hline \multicolumn{5}{|c|}{$\begin{array}{l}\text { Question: Do you think this case should have been reported to } \\
\text { the municipal coroner? }\end{array}$} \\
\hline MFM specialist & $44(70)^{\mathrm{a}}$ & $19(30)^{a}$ & - & \\
\hline Neonatologist & $37(37)^{a}$ & $49(49)^{a}$ & $13(13)^{a}$ & \\
\hline Total & $81(50)$ & $68(42)$ & $13(8)$ & 0.0015 \\
\hline \multicolumn{5}{|c|}{$\begin{array}{l}\text { Would you be willing to report this case to an expert committee } \\
\text { of the Dutch Society of Obstetrics and Gynecology for an } \\
\text { internal audit? }\end{array}$} \\
\hline MFM specialist & $51(85)^{\mathrm{a}}$ & $9(15)^{a}$ & - & \\
\hline Neonatologist & $63(66)^{a}$ & $24(25)^{a}$ & $9(9)^{a}$ & \\
\hline Total & $114(73)$ & $33(21)$ & $9(6)$ & 0.1067 \\
\hline \multicolumn{5}{|c|}{$\begin{array}{l}\text { Do you think such cases should be reported to an expert } \\
\text { committee appointed by the Ministries of Health and Justice? }\end{array}$} \\
\hline MFM specialist & $18(30)^{\mathrm{a}}$ & $35(58)^{a}$ & $7(12)^{a}$ & \\
\hline Neonatologist & $32(33)^{a}$ & $42(44)^{a}$ & $22(23)^{a}$ & \\
\hline Total & $51(33)$ & $77(49)$ & $29(18)$ & 0.3579 \\
\hline
\end{tabular}

Note: Numbers are presented as absolute numbers (\%) according to profession.

apercentages are shown as percentages within the profession. 
Table 3 Answers to the questions on case 2

\begin{tabular}{|c|c|c|c|c|}
\hline Profession & Yes (\%) & No (\%) & $\begin{array}{l}\text { No answer } \\
(\%)\end{array}$ & $p$-Value \\
\hline \multicolumn{5}{|c|}{$\begin{array}{l}\text { Question: Do you agree with the chosen management to } \\
\text { prolong the pregnancy to reach a viable term for the fetus? }\end{array}$} \\
\hline MFM specialists & $5(8)^{a}$ & $50(82)^{a}$ & $6(10)^{a}$ & \\
\hline Neonatologists & $21(22)^{a}$ & $49(52)^{a}$ & $25(26)^{a}$ & \\
\hline Total & $26(17)$ & $99(63)$ & $31(20)$ & 0.0042 \\
\hline \multicolumn{5}{|c|}{$\begin{array}{l}\text { Question: Do you think a pregnancy should be terminated } \\
\text { immediately after an eclamptic seizure? }\end{array}$} \\
\hline MFM specialists & $42(75)^{a}$ & $12(21)^{a}$ & $2(4)^{a}$ & \\
\hline Neonatologists & $36(38)^{a}$ & $16(17)^{\mathrm{a}}$ & $43(45)^{a}$ & \\
\hline Total & $78(52)$ & $28(18)$ & $45(30)$ & 0.3808 \\
\hline \multicolumn{5}{|c|}{$\begin{array}{l}\text { Question: In this case would you have performed a caesarean } \\
\text { section before GA of } 25 \text { weeks? }\end{array}$} \\
\hline MFM specialists & $13(23)^{a}$ & $38(68)^{a}$ & $5(9)^{a}$ & \\
\hline Neonatologists & $37(39)^{a}$ & $33(35)^{a}$ & $25(26)^{a}$ & \\
\hline Total & $50(33)$ & $71(47)$ & $30(20)$ & 0.0029 \\
\hline
\end{tabular}

Note: Numbers are presented as absolute numbers according to profession. apercentages are shown as percentages within the profession.

and neonatologists on management, reporting, and auditing of two exemplary cases. In general, immediate delivery is considered to be the only effective treatment for the mother in cases of severe maternal illness, such as severe early-onset pre-eclampsia. ${ }^{8}$ Our survey indicates that the majority of Dutch MFM specialists and neonatologists agree to report late termination of pregnancy for maternal indications to a committee of medical experts for auditing purposes but not to the District Attorney who may recommend legal prosecution. This opinion is based on the thought that fear for legal prosecution could lead to postponing induction of labor, the only effective treatment, in this way putting the mother at an unacceptable risk for severe morbidity and mortality. ${ }^{8}$ In the Netherlands, pre-eclampsia is still the leading cause of direct maternal mortality and twice as frequent as thromboembolism. In the United Kingdom, the reverse is true. ${ }^{9,10}$

We presented two cases to all Dutch MFM specialists and neonatologists. The first case presented a pre-eclamptic woman whose fetus was severely growth-restricted, the estimated fetal weight being 359 grams. Termination of pregnancy was judged necessary because of the maternal situation. No fetal monitoring was performed, nor was there willingness to perform a caesarean section, or active neonatal resuscitation. Caesarean sections at an extreme premature gestational age are associated with a high risk of maternal morbidity (23\% after caesarean delivery vs. 3.5\% after vaginal delivery $)^{11}$ and has increased risk for complications in subsequent pregnancies. ${ }^{12}$

Some answers revealed a significant difference in opinion between MFM specialists and neonatologists. The first concern of the MFM specialists is the health of the women. The first concern of the neonatologists is to achieve a gestational age as favorable as possible for the newborn. In case 2 this difference in view is the most obvious. The MFM specialists were less inclined to prolong pregnancy and less willing to recommend a caesarean section at a periviable gestational age because of the possible risks for the mother's health. The neonatologists were more willing to prolong the pregnancy and recommend a caesarean section, in the hope to increase the chances for newborn survival. Dutch guidelines are in place to recommend whether or not to start active neonatal management in case of spontaneous extreme preterm birth for appropriate for gestational age infants. The latest guideline dating September 2010, recommends intubation and ventilation from 24 weeks onwards and cardiac resuscitation from 25 weeks onwards. Estimated fetal weight limits are not included. ${ }^{13}$ The American Association of Pediatrics (AAP) has established policies regarding resuscitation at the limits of viability and advises to base management decisions on an assessment of the infant's medical condition, physiologic maturity, and probabilities of death and/or severe disability. ${ }^{14}$ But they also state that as in any pregnancy, obstetric interventions should be undertaken only after a discussion with the family on individual risks and benefits of management options. Parents should be given the choice for palliative care alongside the option to attempt resuscitation. ${ }^{15}$ In case of pre-eclampsia decisions to delay delivery may result in worsening of the maternal condition and fetal growth in a compromised environment. The AAP advises health care providers to consider these risks in the context of periviable gestational age and expected outcome for the neonate and discuss these risks with the parents. ${ }^{15}$

A limitation of this study is the response rate of $37 \%$ (34\% of the MFM specialists and $39 \%$ of the neonatologists). We invited all registered MFM specialists as well as all registered neonatologists; however, not all registered MFM specialists and neonatologists are employed in tertiary centers where these women are treated. Unfamiliarity with these complicated issues might have caused the response rate of $37 \%$. Strength of the study is that the survey was sent to the MFM specialists and neonatologists separately. Results show a marked difference in viewpoint on whether or not to prolong pregnancies or perform a caesarean section in these cases. These differences in viewpoints should be taken into account when discussing cases in a clinical setting.

\section{Conclusion}

This study investigated the opinion of medical professionals on management, reporting, and auditing late termination of pregnancy for maternal indications at a periviable gestational age. The majority of MFM specialists and neonatologists would be willing to report these terminations to a medical expert committee for internal audit but not for legal assessment. We hope that the results of this study will be useful to open the discussion between professionals and promote transparency as well as a positive attitude toward reporting and auditing.

Conflict of Interest

None. 


\section{References}

1 Wetboek online. Available from: www.wetboek-online.nl/wet/ $\mathrm{Sr} /$ 82a.htlm; accessed September 25, 2018

2 Jaarrapportage 2014 van de Wet afbreking zwangerschap. Inspectie voor de Gezondheidszorg, Ministerie van Volksgezondheid, Welzijn en Sport. Available from: www.igz.nl. Accessed October 15, 2015

3 www.wetten.overheid.nl/wet_op_de_lijkbezorging; accessed September 25, 2018

4 NVOG modelprotocol LZA: Medisch handelen late zwangerschapsafbreking 2007

5 Regeling beoordelingscommissie late zwangerschapsafbreking en levensbeëindiging bij pasgeborenen. Staatcourant, nr 3145, 26-012016. Available from: www.wetten.overheid.nl/BWBR0037570. Accessed September 25, 2018

6 van Eerden L, Zeeman GG, Page-Christiaens GC, et al. Termination of pregnancy for maternal indications at the limits of fetal viability: a retrospective cohort study in the Dutch tertiary care centres. BMJ Open 2014;4(06):e005145

7 www.wetten.overheid.nl/wet_medisch_wetenschappelijk_onderzoek_met_mensen; accessed September 25, 2018

8 Belghiti J, Kayem G, Tsatsaris V, Goffinet F, Sibai BM, Haddad B. Benefits and risks of expectant management of severe preeclampsia at less than 26 weeks gestation: the impact of gestational age and severe fetal growth restriction. Am J Obstet Gynecol 2011;205 (05):465.e1-465.e6

9 Schutte JM, Steegers EA, Schuitemaker NW, et al; Netherlands Maternal Mortality Committee. Rise in maternal mortality in the Netherlands. BJOG 2010;117(04):399-406
10 Maternal, Newborn and Infant Clinical Outcome Review Programme. Saving lives, improving mothers' care lessons: learned to inform future maternity care from the uk and ireland confidential enquiries into maternal deaths and morbidity 2009-2012. Knight M, Kenyon S, Brocklehurst P, Neilson J, Shakespeare J, Kurinczuk, JJ, eds. Available from: https://www. npeu.ox.ac.uk/downloads/files/mbrrace-uk/reports/Saving\% 20Lives\%20Improving\%20Mothers\%20Care\%20report\%202014\% 20Full.pdf; accessed September 25, 2018

11 Reddy UM, Rice MM, Grobman WA, et al; Eunice Kennedy Shriver National Institute of Child Health and Human Development Maternal-Fetal Medicine Units Network; Eunice Kennedy Shriver National Institute of Child Health and Human Development Maternal-Fetal Medicine Units Network. Serious maternal complications after early preterm delivery (24-33 weeks' gestation). Am J Obstet Gynecol 2015;213(04):538.e1-538.e9

12 Lannon SMR, Guthrie KA, Vanderhoeven JP, Gammill HS. Uterine rupture risk after periviable cesarean delivery. Obstet Gynecol 2015;125(05):1095-1100

13 Nederlandse richtlijn perinataal beleid bij extreme vroeggeboorte 2010. www.nvog-documenten.nl/index.php. Accessed October 22, 2018

14 Bell EF; American Academy of Pediatrics Committee on Fetus and Newborn. Noninitiation or withdrawal of intensive care for highrisk newborns. Pediatrics 2007;119(02):401-403

15 American College of Obstetricians and Gynecologists; Society for Maternal-Fetal Medicine. ACOG obstetric care consensus no. 3: periviable birth. Obstet Gynecol 2015;126(05):e82-e94 